\title{
Infographic of the Ocular Hypertension Study (OHTS)
}

\author{
Syed Mustafa Ali Ahmad ${ }^{1} \cdot$ Ji Eun Han ${ }^{1} \cdot$ Rashmi G. Mathew ${ }^{1} \cdot$ Christin Henein $^{1}{ }^{1}$
}

Received: 22 October 2020 / Revised: 29 November 2020 / Accepted: 9 December 2020 / Published online: 11 June 2021

(c) The Author(s) 2020. This article is published with open access, corrected publication 2021

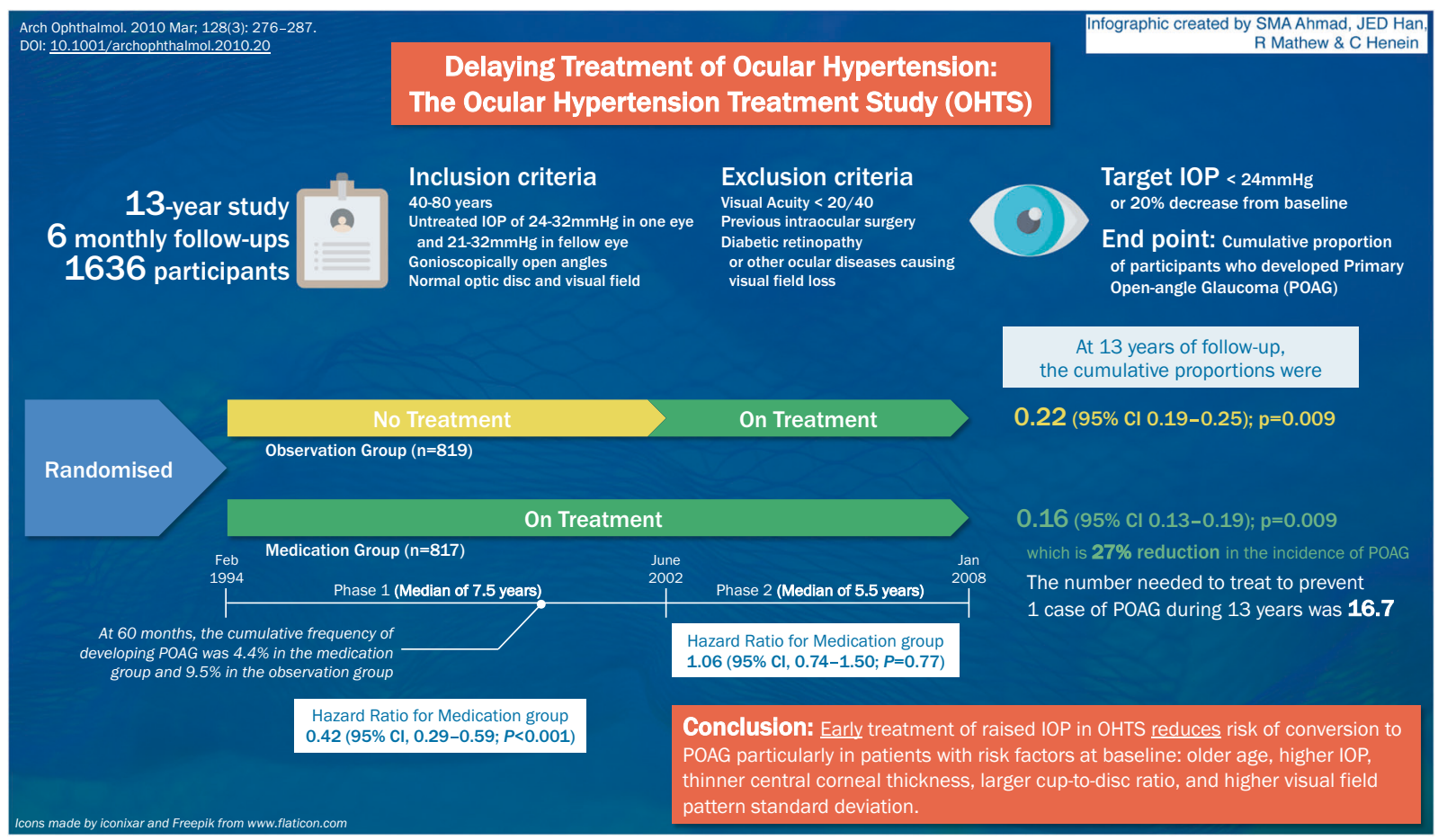

Fig. 1 The Ocular Hypertension Study (OHTS) showed that early treatment of raised intraocular pressures in patients with ocular hypertension reduced the risk of conversion to primary open angle glaucoma, particularly in patients with baseline risk factors. IOP intraocular pressure, POAG primary open angle glaucoma, CI confidence interval.
Open Access This article is licensed under a Creative Commons Attribution 4.0 International License, which permits use, sharing, adaptation, distribution and reproduction in any medium or format, as long as you give appropriate credit to the original author(s) and the source, provide a link to the Creative Commons license, and indicate if changes were made. The images or other third party material in this article are included in the article's Creative Commons license, unless indicated otherwise in a credit line to the material. If material is not included in the article's Creative Commons license and your intended use is not permitted by statutory regulation or exceeds the permitted use, you will need to obtain permission directly from the copyright holder. To view a copy of this license, visit http://creativecommons. org/licenses/by/4.0/.

Rashmi G. Mathew

r.mathew@ucl.ac.uk

1 UCL Institute of Ophthalmology, London, UK 